\title{
Competence Based Management: An Approach towards Effectiveness
}

1*Morteza Fattahpour Marandi

2Seyed Mohammad Kashef

${ }^{3}$ Mir Hassan Seyed Ameri

${ }^{4}$ Reza Shajie

\author{
${ }^{1} \mathrm{PhD}$ Candidate of the Faculty of Physical Education and Sports Science \\ Department of Motor Behavior and Sport Management, University, Urmia, Iran \\ ${ }^{2}$ Associate Professor, Faculty of Physical Education and Sports Science \\ Department of Motor Behavior and Sport Management, University, Urmia, Iran \\ ${ }^{3}$ Associate Professor, Faculty of Physical Education and Sports Science \\ Department of Motor Behavior and Sport Management, University, Urmia, Iran \\ ${ }^{4}$ Assistant Professor at Payame Noor University, Karaj, Iran
}

\section{Doi:10.5901/mjss.2016.v7n4s2p189}

\section{Abstract}

The present study is aimed at discussing the role of competency model on effectiveness among general managers of Iran's departments of sports and youth. This research is a correlative study and its population includes entire employees of general management boards of Iran's departments of sports and youth as well as physical education managers at universities and selected professors of sports management with a previous management experience. The sample was selected as the entire population. In addition, required data for this research are collected through library studies and interviews with experts, authorities and managers of sports domain as well as questionnaires. Upon collection of data, managers' competency model was determined and each item of the model was also scrutinized in terms of significance through one sample t-test. Ultimately, after final analyses, the items were provided in shape of competency model for managers of sports and youth departments. Competence based management could be effective in contexts including employment and training as well as desirable development of the organization.

Keywords: meritocracy, sports managers, competence management, Iran

\section{Introduction}

As time passes, different societies undergo different changes and in this regard, they are differentiated in terms of place and status. A crucial element in differentiation of societies is existence of valuable human resources. Human resource systems are designed and established according to the role and tasks of a particular job in an organization. Human resources is considered as one of the most important and valuable resources of an organization. As a result of scarcity, valuableness and irreplaceability, the role of human resources is crucially important [20]. The foundation of development of every country and every organization is directly related to creativity and innovativeness of human resources. Regarding the importance of the role of nature of organizational management and especially the managers of organizations in formation and establishment of a solid system and structuralizing the atmosphere of organizations as well as the effects of attitudes, strategies and their preferences on cultural elements and organizational behavior and ultimately, the role of managers in outputs and development of the organization and research projects have been noted by different scholars and authors. In fact all these, signify the direct effects of personal characteristics of managers on the status and situation of organizations. Considering the fact that in modern organizations, mangers are viewed as key capitals, it can be claimed that growth and development of human resources is in debt of appropriate selection and implementation of the same resources in different organizational and managerial posts. The Oxford Advanced Learners' Dictionary defines competency as the ability for efficient accomplishment of a task. In terms of vocabulary, competence or competency is defined as having capability, will, expertise, knowledge, merit and qualification. Competencies are a set of knowledge, expertise, personal characteristics, interests, experiences and capabilities in a particular job or role which enables one to perform his or her duties in a state better than optimal. In general, competency and meritocracy are mostly applied for 
selection and appointment of managers in organizations [16]. Mc. Lend (1973) has defined competency as follows: a feature which signifies the performance. In general, competency is defined as a certain characteristic of a person which the person uses and obtains success in a particular role [21].

Management is the most difficult and simultaneously one of the most delicate humane operations and has its own features and characteristics and Lack of one of these features, results in undesirability of the status of management. Nowadays, competency is known as a key promoting element towards obtaining competitive advantage, innovation and effectiveness in every organization. Competence could be considered as a combination of expertise, knowledge and required attitudes for effective accomplishment of a role. In fact, behind every major event and change, there are bold managers and leaders. The role of managers in organizations is important and crucial to the extent that some scholars believe that for an organization to be successful, mere presence of a proper and capable manager is sufficient. In this regard, an organization's failure or success is highly dependable on quality and performance of management. Designing and implementing competency models was limited at first, however during the past few decades, implementation of the aforementioned models have made significance progressions. These models provide the required foundations for different applications of human resource management including planning, absorption and hiring, talent management, development of competencies, performance management, substitution management, evaluation system and etc. Sadati (2011) performed a research and concluded that a significant relationship existed between managerial competencies and managerial effectiveness. He has also claimed that components such as faithfulness, planning and the skill of emotional intelligence have had the highest impacts on determination of managers' effectiveness [9]. Ranjbar et al. (2014) evaluated managers' competency model under a structural equations approach and concluded that expert knowledge, behavioral and intellectual skills, attitudes, validity, personality characteristics, servicing, responsibility and paying attention to religious and moral values are the required and crucial components for competency of managers in the context of healthcare [7]. The term competency is used for description of a set of behaviors which reflect a unitary combination of knowledge, skills, capabilities and incentives. In addition, it is related to performance in a certain organizational role [12]. Thornton and Byham (1982) have explained the components of competency of managers as leadership skills, general management skills, personal skills, communicational skills, creativity and personality characteristics including trust, reliability and compatibility [26]. Dulewicz (1989) has introduced intellectual competencies (strategic perspective and analysis of judgment), personal competencies (convincing, absoluteness), compatibility and consequentialism as four groups of main and crucial competencies for middle managers [22]. Brinkman (2007) has defined the components of competency for executive managers of novice technological corporations as general competencies, social competencies and functional competencies [19]. Naderian (2003) carried out a research titled as "Determining physical education department Managers' skills and competencies". They have developed a managerial model in this context and also they have reported that managers in respective of priority require perceptual, humane and technical skills. They also need the complex set of knowledge of personality characteristics and personal characteristics. On the other hand, middle managers also require knowledge of behavioral and personality characteristics and also, executive managers require the knowledge of behavioral and personality characteristics and personal characteristics [14]. Baziari and Amirtash (2007) have elaborated on appointment of managers with respect to meritocracy in Islamic Republic Iran's department of physical education. They have stated that according to the obtained results, there exists a significant statistical difference between the desired and current statuses of managerial tasks, roles and skills among middle managers and executive managers. The same trend of difference was observed between the current and desired statuses of general and expert appointment criterions. On the other hand, another significant statistical difference was detected between the ideas of experts regarding performance of managers and self-evaluation of managers. In terms of high managers of organizations, however no determined appointment criterions exist at all [2]. Panahi (2013) carried out a research titled as "designing and determining the model of human resources' competencies". They discussed its effects on efficiency in national Iranian company of Petrochemical products. They also discussed a proper model for implementation of competencies of human resources within the company of Iran's national petrochemical productions. They reported that between the strategies of business, roles of human resources and strategies of human resources and the competencies of human resources, exists a significant statistical relation. Asadi Fard (2009) discussed the model of competencies of Iran's governmental managers according to the guidelines of Imam Khomeini and under the approach of input based theory strategy. This research has signified and introduced the main components of managers' competency which are being Islamic, being popular, being in service, ignoring personal benefits, responsibility, responsiveness and personal competencies [1]. Ruin (2011) discussed the extent of impacts of managers' competence on job burnout among police forces. He reported that the results of his researches showed that managers' competence characteristics including knowledge, expertise, experience and capability have deteriorating effects on the process of burnout among employees, however the observed difference is not statistically significant. Other findings of this research indicated that managerial 
education and related previous working experience have significant effects on success among managers. On the other hand, managers' experience was found to have significant negative effects on authoritarianism [8]. Yeganegi (2011) discussed the role of managers' competence on effectiveness of management within the Qazvin province communications company. He stated that a correlation exists between managers' social and personal competence and effectiveness of management. He also found a significant relation between the entire components of managers' competencies and their effectiveness. However no significant relation was observed between managers' managerial skills, personality characteristics and attitudes and effectiveness of management [18]. Ghasemi et al. (2015) carried out a research in which they reported four meritocracy dimensions for middle managers of the departments of sports and youths. These dimensions included super competence, social competence, functional competence and cognitive competence [11].

Considering the deployed and effective role it plays in accomplishment of affairs, Iran's bureaucratic system is considered as one of the most important infrastructures of development. In fact denying it, results in irreparable losses along the way towards realization of goals of Islamic Republic of Iran as well as realization of intended programs and satisfaction of people and etc. [17]. With respect to the importance of this issue and concerns of Iran's authorities and also lack of previous and general researches in this context, the need for paying more attention to this domain is felt more than before. In addition, by discussing and investigating developed organizations and communities in the context of management of organizations, it turns out that without expert, wise and competent managers, no organization can reach sustainable successes.

The department of sports and youths was formed through integration of organization of physical education and national organization of youth in 2011. This organization is the highest source for addressing issues related to sports and youths in Iran. The vast network of department of sports and youths is structured in form of organizations throughout Iran. This department is tasked with the heavy and crucial duty of leading and managing the affairs related to sports and youths throughout the country of Iran. The management of departments of sports and youths which are active in the context of sports and youths is a highly difficult and exhausting task and requires special features and characteristics. As two important issues among every humane society in every place on earth; sports and youths are the main elements of creating happiness and enthusiasm among the public and integration of these two elements (sports and youths) can act as a driving force and have great impacts on dynamicity of a society whether being a town, a province or a country. On this basis, paying attention to competence management and selecting criterions and components of managers' competence in the context of sports is crucially important. With respect to the fact that criterions of competence are different among different communities and organizations, the main aim of this research project has been set to design and determine a model for competency of managers of sports organizations in Iran. By this model, required knowledge, skills, characteristics and personal merits for managers of Iran's departments of sports and youths can be determined. Also the main objective of this study is to determine a competency model for managers of Iran's departments of sports and youths.

\section{Research Methods}

In terms of goal, this study is considered as a research and development project. The main goal of such studies is to codify plans, programs and etc. also, in terms of manner of measurement of research variables; this study is a qualitative study. A qualitative study uses data obtained from interviews, documents and observations for perception and determination of social phenomena. For discussing the issues related to organization and managerial affairs, the researcher selects a research method. During the past few decades the quantitative approach was the dominant approach over managerial researches; but since some of organizational phenomena especially phenomena which are engaged with human behavior, cannot be subjectively observed, researchers have started to use qualitative methods as well. This research implements a grounded theory method. Considering that the author intended to discuss the experiences, knowledge, awareness, thoughts and views of individuals engaged with managerial duties in order to propose a theory, the Grounded theory method was selected for this research. In this method, the hypothesis raised from data is a qualitative research method by the use of which, and by the use of a series of data, a theory is formed. The population of this research includes the scholars in terms of selecting and appointing governmental executive managers. These individuals include a number of MPs, officials and provincial administrators in the social sphere, sport management professionals, professors and faculty members of University Sports Management, managers and experts in the field of Physical Education and Sports Management. Considering the applied research method, and performance of interviews for the purpose of data collection, sampling was performed through two methods of theoretical sampling and snowball sampling. The method of theoretical sampling which is known as the dominant method in terms of grounded theories 
requires the selection of samples in a way that they are helpful towards formation of the intended theory. In theoretical method, at first the author uses his or her own possibilities and judgments selects a series of sources including libraries, articles, interviews and observations. Afterwards, the author looks for samples which may help completing the theory. Also in the method of snowball sampling, social networks and friends with similar characteristics are used for collection of samples. When the researcher found a few number of samples with desired characteristics, he would ask them to introduce other people who they know and they think are similar to them in terms of personality and personal characteristics. This research has employed the sampling methods of snowball sampling and theoretical sampling. Also data collection method in this research includes investigation of documents found in library studies as well as interviews with experts and scholars and review of obtained indexes by experts, authorities, scholars and managers in the domain of sports. In this regard, components of managers' competence are determined according to the data obtained from credible scientific sources and interviews. The software of Atlas Ti V6.0 was used for open, axial and conceptual encoding and categorization [10].

\section{Results and Findings}

In order to obtain data capable of fulfilling the questions of this research, semi-structures and deep interviews were held with research group. In these interviews which varied between 230 to 50 minutes in terms of duration, the addressed issues were pre-exposed to interviewees so that they would take part with previous knowledge and preparation. After completion of interviews, the data were typed into the Atlas software in for of text files. After reviewing the files, the process of open, axial and selective encoding was completed by the use of software. Figure1.

Demographic features of the population of research are provided in figure1. As you can see, most of the participants hold M.A degrees and have managerial experiences of more than 14 years in Iran's departments.

Table 1. Demographic features of research participants

\begin{tabular}{|l|c|c|l|}
\hline Education & Average management experience (years) & Number & Group \\
\hline M.A and Ph.D. & 14 & 4 & M.Ps \\
\hline M.A and Ph.D. & 12 & 6 & University physical education managers \\
\hline Ph.D. & 18 & 6 & Sports management professors \\
\hline M.A and Ph.D. & 14 & 4 & Scholars of social domains \\
\hline
\end{tabular}

There are three encoding methods available for the grounded theory method. These include open, axial and selective encoding. Open encoding is an analytic process through which concepts are identified and respectively, their dimensions are explored in data. At this phase, the theorist of the grounded theory forms the primary categories regarding the studied phenomenon through categorization of data. Axial encoding is the process of relating categories to sub-categories. The reason for this type of encoding is that encoding in this fashion is done around a single axis. The axial encoding is also the process of integration and optimization of categories in a way that a theory is resulted [5]. In this research, after the open, axial and selective encodings, the data obtained from interviews were categorized in 92 concepts, 12 categories and three levels. Finally, after ultimate analyses, they were introduced as the model of competency for managers of Iran's departments of sports and youths. The theory resulted from this grounded theory can be expressed in three different manners. In the first case, in form of an objective encoding model including a series of constituents, the model is presented with lines showing the relations between categories. In figure1, a sample of this method is proposed for categorization of organizational competencies. The second case is a set of hypotheses which indicate constituent categories and concepts which for the theory. The third case is a narrative representation of results [5]. According to the axial encoding phase, the following theorems were obtained (table2). 


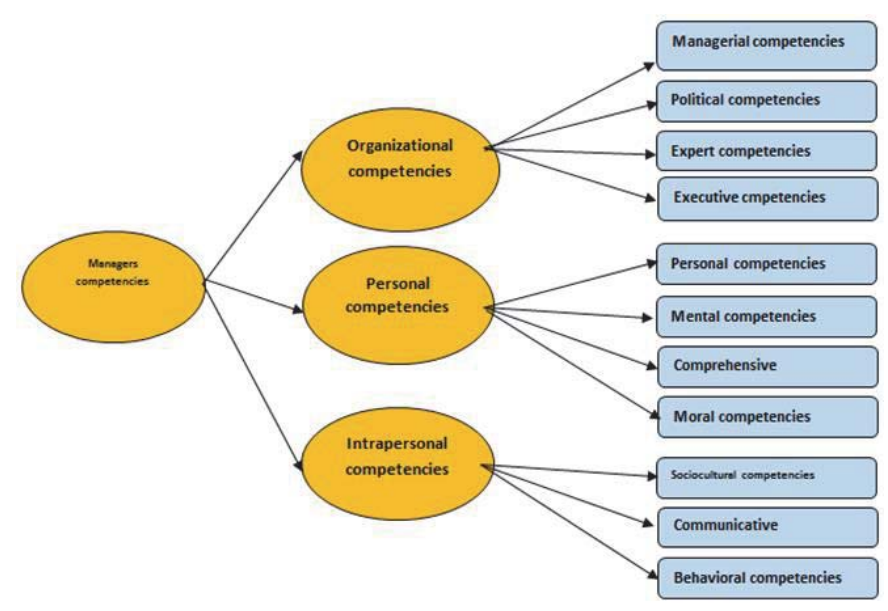

Figure 1. Model obtained from qualitative phase of research

Theoretical theorems indicate generalized relations between a category and its concepts and determined categories.

Theorems indicate existence of conceptual relations. This is while a hypothesis requires evaluable relations and since the theorizing approach of grounded theories produces conceptual relations, it was preferred to use the term Theorem [5]. Theorems related to this research include:

Theorem1: organizational competencies in the competence model of managers of Iran's departments of sports and youth include concepts including managerial competencies (stress management, conflict management, different management, change management, strategic management, resource management, performance management, management of ambiguity, complexity management, crisis management, information management, project management, power planning, decision-making skills, delegation, deputy Fact, knowledge resources, strategic thinking and familiarity with financial management); political competencies (political knowledge, political insight and lack of politicization); operational competencies (critical thinking, systematic approach, results-oriented, customer-focused, professional knowledge, coaching, control, accountability, risk-taking, negotiation skills, motivation, result-oriented, change leadership, conceptual thinking, logical thinking, empowerment, learning-centered, team leadership, continuous improvement, crosscultural intelligence, effective communication, participation, knowledge and global intelligence / mind World), professional competence (nobility to the work, being of community of sports, history of sports management, sports community acceptance and popularity in athletic society).

Theorem 2: personal competencies in the competence model of managers of Iran's departments of sports and youth include concepts including Personal competencies (to avoid the rush, popularity and client, Allure, having a simple lifestyle, courage, time management, flexibility / adaptability, criticism, sublime, determination, creativity, innovation, business acumen and independence); moral competencies (respect for justice and fairness, resistance against problems, good mood and cheerfulness, humility, openness and ethical behavior); the competencies of conscience (God centeredness, honesty and integrity, insight, compliance with others rights, adherence to Islam and piety); psychological competencies (emotional intelligence, spontaneity, self-knowledge, self-confidence and tolerance of dissenting opinion).

Theorem3: Intrapersonal competencies in the model of competency of managers of Iran's departments of sports and youths includes concepts such as socio-cultural competencies (popularity, lack of criminal records, cleanness); communicative competence (communicational skills, power and effectiveness, counseling and the ability for building networks) and behavioral competencies (discipline, being an example and respecting others).

Table 2. Correlation between components of competence

\begin{tabular}{|l|l|}
\hline Organizational competence & component \\
\hline $\mathrm{R}=0 / 78 \mathrm{P}=(0.001)$ & Managerial competence \\
\hline $\mathrm{R}=0 / 56 \mathrm{P}=(0.001)$ & Political competence \\
\hline $\mathrm{R}=0 / 91 \mathrm{P}=(0.001)$ & Operational competence \\
\hline
\end{tabular}




\begin{tabular}{|l|l|}
\hline $\mathrm{R}=0 / 87, \mathrm{P}=(0.001)$ & Expert competence \\
\hline $\mathrm{Personal}$ competence & component \\
\hline $\mathrm{R}=0 / 95, \mathrm{P}=(0.001)$ & Personal competence \\
\hline $\mathrm{R}=0 / 60 \mathrm{P}=(0.001)$ & Moral competence \\
\hline $\mathrm{R}=0 / 50 \mathrm{P}=(0.001)$ & Religious competence \\
\hline $\mathrm{R}=0 / 54, \mathrm{P}=(0.001)$ & Mental competence \\
\hline Intrapersonal competence & competence \\
\hline $\mathrm{R}=0 / 77 \mathrm{P}=(0.001)$ & sociocultural \\
\hline $\mathrm{R}=0 / 90 \mathrm{P}=(0.001)$ & communicative \\
\hline $\mathrm{R}=0 / 86 \mathrm{P}=(0.001)$ & behavioral \\
\hline $\mathrm{C}$ ompetency of managers of sports and youth departments & component \\
\hline $\mathrm{R}=0 / 93 \mathrm{P}=(0.001)$ & organizational \\
\hline $\mathrm{R}=0 / 82, \mathrm{P}=(0.001)$ & personal \\
\hline $\mathrm{R}=0 / 40, \mathrm{P}=(0.001)$ & intrapersonal \\
\hline
\end{tabular}

\section{Discussion and Conclusions}

In today's world, sports have found multidimensional layers. The applications of the phenomenon of sports are not only summarized in personal health. Rather, nowadays, sports are viewed as a multidimensional phenomenon which in terms of the personal dimension is mostly related to health, activity and capability. Also in terms of social dimension it improves the indexes of health and life satisfaction which is the most important goal of the UN regarding human development. In terms of the political dimension, sports improve one's national identity and also improve social bonding. Sociologists have considered sports as the most important strategy for improvement and development of social capitals. Also in terms of the view of education, sports provide a suitable context for growth of desirable moral characteristics such as goodness, patience, team work, collaboration, hard work, participation, adherence to laws, and sociability. Also in terms of the view of management and economics, sports are considered as one of the most important fruitful industries throughout the entire globe. In this regard it has been said that in some developed countries, revenues gained from the industry of sports are in first to fifth ranks. Nowadays, sports have the tenth place in economic transactions in the entire world and this place is improving by time. If a country such as Iran draws a 20 year perspective for sports, it can obtain as much revenue as it can obtain from Oil industry. Anyway, nowadays sports are considered as one of the best ways for employment and improvement of working environment and also one of the best advertising spaces for development of commercial goals of every organization and company.

On one hand, as a result of the status they have, managers can cause their systems valuable benefits or even irreparable losses. On this basis identifying the competencies of managers of sports related organizations is a subject which can be considered as the first step for an evolution in management of organizations related to sports. It also seems that paying attention to criterions of this research and implementing them can be way for optimization of qualities of managers of sports organizations which ultimately results in improved efficiency in this domain. While discussing the results obtained from previous researches it was turned out that the results of the present study are consistent with the results obtained by Thornton and Byham (1982); Naderian (2003); Baziari and Amirtash (2007); Panahi (2013); Asadi Fard (2009); Ruin (2011); Yeganegi (2011) and Ghasemi et al. (2015). Rapid acceptance and development of the approach of organizational competency and implementing it in employees' developmental programs are among the boldest benefits embedded in this approach. By investigating the systems of human resources of organizations; it turns out that systems such as education, performance evaluation, absorption and etc. lack required and desirable continuity and relations. And therefore, most of the programs related to human resources result in lack of efficiency of human resource systems. In other words, existence of powerful relations and overlaps between the subsystems of human resources requires the mutual empowerment of each system. Ultimately it seems necessary to make the systems of human resources dynamic and systematic systems. One of the best and most suitable approaches for obtaining this goal is to implement the approach of competence in management of human resources.

In contrast to surface views of some authors, competence models are not unique. Each large and leading organization has its own competence model and they try to complete and reform their own model of competence. The variety observable in competence models and the existing categorizations in this domain are reasons for this claim. On the other hand, preliminary investigations have revealed that only a few and limited number of previous studies address the same view. The concept of managers' competence is a subject which is the center of attentions in these days. Therefore, investigating and researching in this context and obtaining a general model can be very helpful for increased 
development of sports organizations. On the other hand, organizations' success is to a large extent dependent on competence, capability and authenticity of their managers. In meritocratic societies it has been concluded that if attention is paid to traditional views, then the organization will lag behind on the way towards competition and activity. This is while ignoring the need for appointment of merit managers leads to failure of the organization towards realization of goals and missions [15]. Experience has shown that most managers are interested in providing their organizations with a competence model but they don't know what parameters they need for doing so [25]. In an environment which is exposed to continuous changes, it is impossible to have a successful management without preparing competent employees. In current world, organizations strive to absorb and maintain the most competent of managers as a competitive advantage. Competence is defined a s a set of features and characteristics which plays a role in a successful job performance. These competencies include knowledge, expertise, capabilities and characteristics such as values, incentives, innovations and self-control. A dominant traditional view in Iran's management literature is that sports should be left for athletes. Expertise in one or some sports fields is the perquisite for being appointed as a sports manager in Iran. However, it can never be sufficient. With respect to different applications of sports and promotion of sports to a worldwide phenomenon, we are obliged to discuss and identify the necessary characteristics and competencies for being appointed to major sports management posts. Organizations require and need effective and efficient employees in order to be able to obtain their goals in terms of all-aspect growth and development. As the main decision makers, managers play a crucial role in success or even failure of an organization [24].

Among the important results and applications of using this model it can be referred to the following points: 1) evaluation of managers of Iran's departments of sports and youth according to the components yielded from this research; 2) optimization of performance of Iran's departments of sports and youth as a result of appointment of competent managers; 3) optimization of the status of implementing human resources in Iran's department of sports and youths towards improvement of these departments' performance, and 4) identification of educational needs of managers in terms of education of sports managers and 5) applying the trainings of sports managers and etc.

\section{References}

Asadi N; Sajadi s N; goudarzi M; moradi A. (2015). Determining the Competencies of Sports Event Managers, Journal of Sport Management, 7(2), 159-174. (Persian)

Asadifard, R. Khaef Elah, A. a. \& rezaeiyan, a. (2011). Competency Model of Iranian Public Administers: Grounded Theory Approach. Iranian Public Administration, 3(8), 75-92... (Persian)

Ball, J. Simpson, S. Ardovino, P. (2008).Leadership competencies of university recreational directors in Wisconsin. Recreational Sports Journal, 23, 3-10.

Baziari, E, Amirtash, AM(2006) Managers, employing on the bases of meritocracy in Physical Education Organization, Research In Sport Management And motor behavior,4(7), 1-10. (Persian)

Brinckmann, J. (2007). Competence of Top Management Teams and Success of New Technology-Based Firms. Publisher Gabler, Frankfurt Deutscher Universitäts-Verlag.p304

Danaiefard H, Emami S M. (2008). Strategies of Qualitative Research A Reflection on Grounded Theory, Sterategic Management Thought, 1(2), 69-97. (Persian)

Dulewicz, V. (1989). Assessment centers as the route to competence.Personnel Management, 56-59.

Fathi S. (1391). The role of management in the performance merits managers of sports organizations Qom province of Iran, Tehran, Islamic Azad University, Central Tehran Branch Master's thesis, 12. (Persian)

Ganj Ali A, Timurian M, Abdulhoseinzadeh M. (2013) The criteria of competency in the Quran, the Muslim and management studies, 3:1(7), 91- 114. (Persian)

Ghasemi Seyyed H, Honari H, Rezai Soufi M, Momenifar (2015) Designing a Core Competencies Pattern for Aointment of Middle Sport Managers in Iranian Ministry of Sports and Youth, Quarterly Journal of Strategic Studies in Sport and Youth,26, 23-40. (Persian)

Hanna, A. Ibrahim, M. Lotfallah, W. Iskandar, K. and Russell, J. (2016). Modeling Project Manager Competency An Integrated Mathematical Aroach. J. Constr. Eng. Manage, 10.1061/(ASCE)CO.1943-7862.0001141, 04016029.

Karami M, Saleh M. (2009) competency-based development (New Approach in Training and Development Manager) 1th printing, Iran, Tehran, Ayezh Pres, 1-10. (Persian)

Marjoribanks T, Farquharson K. (2016).Contesting competence Chief executive officers and leadership in Australian Football League clubs. Marketing Intelligence \& Planning, 34(2), 188-202

Motaghi MH, Beheshtifar M (2006).The relationship between personality traits and motivational managers with their assessment of their success in Kerman public organizations, Journal of Knowledge Management, 19(73), 89-104. (Persian)

Naderi Khorshidi A, Nikokar G, Karami M. (2010). A Model for Appointing Managers. Journal of Research in Human Resources Management, 1(4), 91-113. (Persian)

Naderian, M. \& Soltan Hoseini, M. (2012). Technichal skills and abilities of sport executives Indicators and standards, according to sport managers' point of view. Scientific Journal Management System, 1(2), 11-18. (Persian) 
Nasr Esfahani, M, Nasr-Esfahani, A. (2010) meritocracy in society management with an emphasis on political ideas of Imam Ali (AS), political knowledge, 2,141-160. (Persian)

Panahi, B, (2012) define and design a competency model with its effects on the productivity of human resources at the National Petrochemical Company of Iran, Iran, Tehran, Payam Noor University, PhD thesis, 341. (Persian)

Ranjbar, H. Haghdoost, A.A. Salsali, M. Khoshdel, A. Soleimani, M. \& Bahrami, N. (2012). Sampling in qualitative research: A Guide for beginning. Ann Mil Health Sci Res, 10(3), 238-250. (Persian)

Ranjbar, M. Khaef Elahi, A, Danaee Fard, H, \& Fani, A. (2014). Measurig Competency Model for Managers in the Health Sector (Structural Equation Modeling Approach). Journal of Mazandaran University of Medical Sciences, 23(109), 104-113. (Persian)

Rappe C, Zwick T. (2007) "Developing leadership competence of production unit managers". Journal of Management Development, 26(4) pp: 312-301

Roein, MJ. (2010) Evaluation of the effect of managers' competency on job burnout in NAJA personnel, Iran, Tehran, Tarbiat Modarres University, a master's thesis, 169. (Persian)

Sadati, A. (2010). The effect of government on the effectiveness of managerial competencies Security Manager in Tehran state universities and research institutes affiliated master's thesis, Tehran, Tarbiat Modarres University. 20-30. (Persian)

Syed Javadein, S R, Asfydany, M R (2010) grounded theory and software Atlas.ti, First Edition, Tehran, Institute for Trade Studies and Research.160. (Persian)

The Supreme Administrative Council (2013) Road map administrative reform, one hundred and sixty-second session of the meeting, 76. (Persian)

Yeganegi, A. (2010). Examining the Relationship between Managers' Competencies and Management Effectiveness: The Case of Communication Company of Qazvin. Journal of Development \& Evolution Mnagement, 1389(pre.no.5), 57-67.

Yu, M. Xiao, D. (2015) International Conference on Informatization in Education, Management and Business (IEMB 2015), Guangzhou, China, September 12-13, 1053-1057 